\title{
ARTERIAL HYPERTENSION AND RETINAL CHANGES
}

\author{
BY \\ N. Pines, M.B., L.M.S.S.A.L., \\ LONDON
}

In offering to the attention of the reader the result of my investigations of the correlation between arterial hypertension and retinal changes, I feel that it is necessary to answer the possible question : What else can be added to this particular subject, after the brilliant work and investigation published by such authorities as the late Marcus Gunn, or Foster Moore, or Maitland Ramsay, especially if the investigator be a general practitioner, even if he have some experience in ophthalmology? But the specialists themselves are partially responsible for this: they so often appeal to the general practitioner, asking him to investigate or observe and to make deductions, that 1 was tempted. On the other hand, the patients who are seen in hospital or consulting practice are for the most part more definite, more or less advanced types of the disease. I had the opportunity of examining patients, many of whom were my panel patients, who came to consult me about disorders which had nothing to do with their visual organs nor with hypertension, and I tried to look for arterio-sclerosis of the retinal vessels in the different stages of this pathological process. I could not carry out such complete investigation of my cases, as is possible with hospital in-patients. From this point of view my observations are very incomplete indeed. As to kidneys I only examined the urine for sugar and albumen. I took the specific gravity and called the urine normal if albumen and sugar were absent and the specific gravity was normal. I never determined the quantity of urine in twenty-four hours, I did not perform kidney efficiency tests and did not examine the sediment microscopically. The Wassermann reaction was not performed. When examining the eye, I only noted the objective signs and changes as shown by the electric ophthalmoscope. I did not measure the visual acuity, nor did I examine the field of vision nor sense of colour. These are all very serious defects from the scientific point of view. I tried to carry out my investigations in the simplest possible way, because of the impossibility of performing all these highly technical tests, and because it is my profound conviction that simple observation and careful attention of the examining medical man will always bring forth some valuable result. I have seldom used a mydriatic. When examining the blood pressure the patient sat with the elbow approximately on the same level as the 
apex of the heart. The method was Korotkoff's, and the maximum systolic pressure was verified by palpation. Each patient was examined at least twice at different times. I found that usually by auscultation the systolic blood pressure was a few $\mathrm{mm}$. (10 or so) higher than by palpation. I had to rely entirely on the electric ophthalmoscope, sphygmomanometer and routine examination of the urine, such as can be easily performed in the daily work of a general practitioner. In a few selected cases I had the opportunity of investigating my cases more fully, thanks to the kind co-operation of a few consulting physicians. I consider it my pleasant duty to express my gratitude to $\mathrm{Mr}$. A. H. Levy, for discussing and clearing up many doubtful points, to the Honorary Staff of the London Jewish Hospital and to Dr. Lewis Smith, Dr. J. Parkinson, Dr. A. Rowlands, and Dr. O. Leyton of the London Hospital, for giving me full particulars of their investigations of a few of my cases.

The reader will note also that I very seldom palpated the arteries to investigate their hardness. It is not because I under-estimate the value of palpation, but because I think it very difficult to recognize by palpation, in cases of arterial hypertension, what is the cause of the hardness : real arterio-sclerotic changes or tonic contraction of the muscular tunica media. The arterio-sclerosis of the clinician is something different from the arterio-sclerosis of the pathological anatomist. The latter means by this term sclerosis of the tunica intima; it corresponds to the "athero-sclerosis" of Marchand, angio-sclerosis of English authors, and the ultimate form is atheromatosis. Athero-sclerosis chiefly attacks the type of artery where the elastic fibres are predominant-aorta and large arteries. But it is this type of sclerosis, even if the radial artery itself be involved, that cannot be detected by palpation; and patients with an atheroma of the aorta may have soft radial arteries. In the eye, too, this athero-sclerosis, although it can be seenembolism and thrombosis of the central retinal artery, thrombosis of the central retinal vein-is secondary in frequency to the other type-the arterio-sclerosis of the clinician. In this type of arterio-sclerosis the seat of the pathological process is chiefly in the tunica media. And of the state of the media we can judge by palpation. The hardness of the media may be caused either by degenerative changes in it, brought on by proliferation of its elastic and connective tissue fibres and by diminution of the muscular fibres, which is followed by calcification-the arteriosclerosis of all persons of advanced age, caused by the wear and tear of life- "chacun a l'âge de ses artères"-or by a tonic contraction of the tunica media-hypertension-which may exist in a vascular system entirely free from the above-mentioned arteriosclerotic changes. The study of cases of hyperpiesis has confirmed 
what is well known, namely, that hyperpiesis may exist and yet the patient, during life, may show few or no symptoms of the disorder. Even repeated and detailed clinical examination has failed to show any of the signs, other than hyperpiesis-no signs or symptoms of cardiac hypertrophy and none of vascular changes (Batty Shaw $\left.{ }^{(14)}\right)$.

These are the two kinds of clinical arterio-sclerosis which are more of ten seen by a general practitioner, and which show changes in the retinal vessels. The correlation between these retinal changes and the results of the sphygmomanometric examination is the subject of this paper. I was chiefly interested in the question : Why do we so rarely see definite and advanced arterio-sclerotic changes in the retinal vessels of aged people who clinically present definite and advanced sclerosis of the general arterial system, and who often show signs of arterio-sclerosis of the central nervous system? And how far can you go in the prognosis of your patient when you know his blood pressure and have examined his urine and his fundi?

\section{Normal Fundus}

The retinal arteries and arterioles, which can be seen by the ophthalmoscope, possess a relatively weakly developed arterial wall, especially of the muscular part. The connective tissue of the tunica adventitia is sharply differentiated from the surrounding nervous tissue (Salzmann $\left.{ }^{(15)}\right)$. The arteries are weakly supported by the connective tissue round them because this tissue-Müller's fibres and the neuroglia-is very delicate in the retina. Those two peculiarities make the vessels, especially the arteries, translucent. More often the arteries cross the veins, but sometimes vice versa. Sometimes in the same patient in one eye the arteries cross the veins, and in the other eye the veins cross the arteries. As far as my experience goes, even in young and healthy persons of the age of 7-25 years it is difficult to decide if the calibre of the vessels he normal or not. The calibre of the vessels varies considerably in different subjects and therefore it is difficult to define how far any vessel is wider than a normal one ; or this widening or narrowing of the vessel may be so definite that it is easily distinguishable. Therefore I very seldom describe the calibre of the retinal vessels. Buf if the same vessel shows differences of calibre in various parts of its length, then this will be a serious pathological feature, as is justly pointed out by Foster Moore. It is true that I have never seen this phenomenon present alone-usually you can find other signs of profound pathological changes in the same eye.

Quite a different significance is attached to the translucency of the retinal vessels. Here we have an important and certain basis 
for forming an opinion about the state of the wall of the vessel. The larger retinal vessels lie chiefly in the nerve fibre layer and partly in the layer of ganglion cells and they project very slightly, if at all, above the surface of the retina. At the points where they cross one another it is easy to determine their translucency. In a young and normal eye the artery or vein allows one to see dimly the underlying vessel-with one exception-if the superior or inferior main branch crosses the corresponding large vein, or vice versa, the blood column is so thick that the underlying vessel cannot be seen at all. This is the case even in children. Therefore the translucency of the vessels can only be stated to be normal in the medium and small arterial or venous branches, but not in the whole length of the vessel up to the point where it joins the disc. Marcus Gunn states : "that normally in consequence of the darkness of the venous blood stream, an artery is invisible through a vein." I could easily see an artery through a vein in all medium and small branches in a normal eye, although I agree that the translucency of the artery, because of the smaller blood column, is greater than that of the vein. I think that the use of the electric ophthalmoscope allows one to pour into the eye a luminous beam of such intensity that the translucency of the vessel becomes much higher. This opinion of Gunn may possibly be explained by the fact that he used an ordinary reflecting ophthalmoscope. The translucency of the vessels, in my opinion, is a fact of primary importance in determining whether they are normal or not. My investigations have led me to the conclusion that if this translucency of the vessels is gone, it is a certain sign of arterio-sclerotic changes in the wall. Fiven if the tunica media is in a state of tonic contraction, as in cases of pure hypertension, it should still be translucent. The reader will remember, as stated previously, that the middle coat is very weakly developed in the retinal arteries. But if this coat be the seat, not of muscular contraction, but of proliferation of its elastic and fibrous tissue, with a proportional diminution of pure muscular tissue, or of true calcification, then, of course, its optical qualities will be changed and the translucency will disappear first. It is of some interest to find that the translucency in some cases is lost in all vessels, except one or two of the smallest ones. The oldest of my patients, who still preserved the translucency of his retinal vessels is No. 13, aged 65 years. My investigations also showed that I have never found translucency completely absent in one eye and still well preserved in the other. Except the "dotting" of the light reflex and "copper-wire" colour of the arteries, all other arterio-sclerotic changes may be present in one eye and completely absent in the other (deviation of the veins, change of the lumen, etc.), but the translucency of the vessels disappears simultaneously in both eyes. In group No. 1. 
where I put all cases with a normal eye-fundus, the translucency is present in 100 per cent. Special attention is drawn to case No. $1 \%$

Two other signs are strictly connected, as will be easily understood, with the translucency of the vessel wall. These are the light reflex and the colour of the arteries. But their definition is much less reliable than the translucency. Light reflex may be on! stronger, but not dotted. Therefore I preferred to put all the cases where I was not certain of the "dotting" of the light reflex, in the "dotted" category. Even more difficult sometimes is the definition of the colour of the arteries. Is it only slightly changed or already of "copper-wire" colour? Here too, when in doubt, I called them "copper-wire." My statistics show that in group $1 a$, with moderate arterial hypertension, the translucency is gone in $9 \tau$ per cent., but the light reflex is dotted only in 43 per cent. and "copper-wire" colour of the arteries is found in 41 per cent. These changes occur in very much the same proportion but are not nearly as frequent as loss of translucency and hence the latter is of much greater importance. In cases of severe arterial hypertension, No. $1 c$, as it would be only logical to expect, the translucency is gone in 100 per cent., light reflex is dotted in 94 per cent. and arteries of copper-wire colour are found in 88 per cent. Thus, in my opinion, the analysis of the tables shows that $\mathrm{my}$ previous theoretical reasoning is more or less correct. Group No. $1 b$ shows 88 per cent. of translucency gone' and 100 per cent. copper-wire colour and "dotting" of the light reflex, but they are all cases of diabetes mellitus. As a résumé I must say that in all my cases, I have never seen one where there was good translucency of all, or even of a considerable part of the vessels in combination with other signs of arterio-sclerotic changes. The translucency of the vascular wall is one of its most delicate qualities and it diminishes or disappears first of all while other signs are only beginning to show. Therefore I divided all my cases into four groups, guided by this principle of translucency. In group No. 1, I collected all the cases where the fundus is normal as well as both blood pressures. In group No. $1 a$, I put together all the cases where the fundus already showed arterio-sclerotic changes, but the systolic blood pressure was not higher than 200 , and the diastolic not more than 90-95; group No. $1 c$, where the respective readings were 200 or over and 100 or over; group No. $1 b$, all the diabetic cases; and consider separately the cases of $\mathrm{D}$. and $\mathrm{R}$. as of exceptional interest.

Apart from the translucency of the vascular wall, another detail may be seen at the point of crossing. The artery does not interfere with the vein and does not crush it, but only depresses it. The calibre or shape of the vein is not changed, but the portions just before and after the crossing, and the crossed part itself are not 
seen as clearly as the whole vessel. The difference is a very small one, about $0.5 \mathrm{D}$. or so, and altogether this phenomenon is not very often seen (11 per cent.). One can compare this to the depression of a piece of string, if another piece be lying on top of it. The vessels of the retina are fixed by surrounding connective tissue. They are as if they were bound together at the point of crossing.

In his excellent book "Medical Ophthalmology," where the designs of different forms of vessels are most surprising, Foster Moore points out, as an important pathological change, that the veins are crushed by the arteries; they may also be bent or deflected in the direction of the artery. This, of course, is correct. But I have seen this deflection of the vein twice in group No. 1 ( 8 per cent. in 26 cases). In the first case (No. 10) the fundus is normal in every respect, but the systolic, and especially the diastolic, pressure is certainly high for his age. In the second case, No. 21, the translucency is much diminished; the diastolic pressure is decidedly pathological, being 105 . Is the deflection of the vein here caused by early sclerosis of the artery, or is it a congenital condition, aggravated possibly by increased blood pressure?

\section{Arterio-Sclerotic Fundus.}

In case No. 13 the fundus is normal, in spite of the age and definitely marked sclerosis of the general vascular system, bad pyorrhoea and some deafness (sclerotic?). The only suspicious sign is the white lines accompanying the artery at the point of crossing. But his blood pressure is only $130 / 75$. In case No. 12 the translucency of the arteries is gone, but not of the veins. His blood pressure is $190 / 90$. In case No. $5 a$ the translucency only is gone; the outlines of the discs are not clear. Otherwise her fundi are normal, the blood pressure being $130 / 80$. She is an intelligent woman with a knowledge of her medical history. She had a severe puerperal sepsis ten years ago, which kept her life in danger for six months and involved both her kidneys. She has even now many signs of old phlebitis in both legs. In case No. 28 the fundi are normal. He has an arterio-sclerosis of the second degree of the brachial and radial arteries, and his blood pressure is $125 / \tilde{\tau} 0$, with a history of a chronic gastric ulcer. Case No. $3 a$ was under my care for five years. His fundi would be normal, but that the translucency is gone. His blood pressure is now $130 / 85$, but in the past was $160 / 100$. Last summer he had a periostitis of the upper edge of the right orbit on the temporal side, which was caused by a chronic purulent infection of his right frontal sinus, a septic ethmoiditis and septic tonsils. He was 
operated on for all these last year. His periostitis disappeared but later on he developed some signs of irritation of the sympathetic system, possibly connected with intestinal intoxication. Case No. 14 is also worthy of attention. Case No. $1 a$ is a good demonstration of the well-known rule that even generalized arteriosclerosis may not be accompanied by arterial hypertension. Evidently there must be some special toxin which causes arterial hypertension. I will discuss this matter later on. The same applies to cases Nos. 23a, 37a, 38a .

Case No. $42 a$ is worthy of special attention. I was called to see the man-I never examined him before-early one morning, when he was in agony from cardio-vascular pain. Diagnosisangina pectoris(?). Two days later he walked into my surgery telling me that he was feeling better. I found his blood pressure $110 / 90$, pulse 120, arterio-sclerosis of the second degree of the brachial arteries and arterio-sclerotic changes in his fundus. Fearing that he might be a case of coronary thrombosis, I rushed him to a hospital where he was kept in. The physician in charge of the case kindly informed me later that it was a case of coronary thrombosis with a negative Wassermann. The patient is improving now. He has, consequently, a generalized arterio-sclerosis (with athero-sclerosis?) everywhere including the fundi, but his blood pressure is low. Is the cause of this an impairment of his heart, as O'Hare and Walker think, or has he a persistently low blood pressure? It is difficult to decide now. He is obviousiy not a case of the involutionary sclerosis of Allbutt, whose general scheme is so very helpful.

Cases Nos. 11a, 14a, 20a, 16a, 31a I consider to be types of this involutionary arterio-sclerosis with involvement of the retinal vessels and low blood pressure. In case No. $36 a$, I was not certain of the softness of the arteries as shown by palpation, but the diastolic pressure is decidedly raised, especially in view of the low systolic pressure. In case No. 32a the unusually low blood pressure may be explained by the far advanced pulmonary tuberculosis. In case No. $22 a$ the systolic blood pressure is very high for his age, although the diastolic is still normal. Mav I suggest that the toxin is already attacking the retinal vessels, but has not yet produced sufficient irritation or change in the peripheral system to raise the diastolic blood pressure? From the analysis of the tables No. 1 and No. 1a, I draw the conclusions that (1) in involutionary arterio-sclerosis the retinal vessels may be involved in cases without arterial hvpertension, but they may escape this till a very late age (65 vears) if the arterial tension continues to be low and there is no history of toxaemia in the past : (2) hyperpiesis will alwavs bring with it sclerosis of the retinal vessels, the diastolic pressure being especially important. 


\begin{tabular}{c|c|c|c}
\hline Group. & Average Age. & $\begin{array}{c}\text { Average } \\
\text { Systolic } \\
\text { Pressure. }\end{array}$ & $\begin{array}{c}\text { Average } \\
\text { Diastolic } \\
\text { Pressure. }\end{array}$ \\
\hline 1 & 30 & 133 & 82 \\
$1 a$ & 51 & 153 & $93 \frac{1}{2}$ \\
$1 b$ & -54 & 189 & 88 \\
$1 c$ & 59 & 225 & 123 \\
\hline
\end{tabular}

I did not differentiate between the sexes as this is of no importance from our point of view. Foster Moore, when discussing renal retinitis, says : "It is very unusual to meet with retinitis except in the presence of a very considerably increased blood pressure, but retinitis is often absent though the blood pressure is greatly raised." As regards retinitis, this is correct, but in my cases, where the kidneys were not involved or only secondarily involved, sclerosis of the retinal vessels was always present, although in a different degree. If the hypertension is of recent origin, sclerosis of the retinal vessels may not have yet developed completely; some time must elapse before the unknown toxin of hyperpiesis will cause degeneration of the retinal vessels. They may escape when the general system is already degenerated. In some cases the toxin disappears, the blood pressure becomes normal again, but the changes in the retinal vessels are nevertheless permanent. 'I will discuss this matter more fully later on. And now I will analyze some arterio-sclerotic retinal changes in my cases, group No. $1 a$ and No. $1 c$.

In my opinion the only changes one can consider to be pathological are the white lines which accompany the vessels at the points of crossing or on the retina. If they are present only on the disc they may be congenital. If I may be allowed to draw up a scheme in the order of appearances of these changes I would put as first the white lines at the point of crossing or on the disc, as second on the retina near the disc, and as third those on the periphery of the retina. In most cases in the third group these white lines are uninterrupted, but sometimes one part of the vessel between the disc and the periphery may be free from them. These white lines represent in my opinion, a thickened adventitia and sclerosis of the surrounding supporting tissue. As the adventitia is developed principally in the large vessels and less developed in the smaller ones, therefore, these changes must be seen earlier on the disc, where the neuroglia is also more plentiful. The vessels lie between the bundles of the nerve fibres, $i, e$. , where the glia is also lying. The quantity of these nerve fibres in the sagittal meridian of the retina increases in proximity to the disc and reaches 
the maximum on the disc, still preserving their septa gliosa (Salzmann). And as in ophthalmoscopic examination we see the retina in this very direction, therefore, it is that these white lines are seen more often on the disc, even in normal eyes. I must mention here that Römer says that in arterio-sclerosis "the walls of the vessels become opaque because of the thickness. On the arteries appears a white line." Fuchs says that "in the later stages white streaks along the arteries and veins (perivasculitis) and haemorrhages." Marcus Gunn states "changes of the coat of the artery . . . narrowed the blood stream are rarely here accompanied by so much fibrous thickening as to lead to the appearance of the white lines along the vessels." This is quite correct for the later stages of the disease, but not for the early stage. Evidently the white lines will first be seen at the crossing points, where one thickened adventitia lies over another one, which is also thickened, or on the disc, if the reader will remember the above-mentioned anatomical particulars. Accordingly in group No. 1 they are 4 per cent. and 8 per cent., in group No. $1 a, 15$ per cent., 27 per cent., and 5 per cent. But in group No. $1 c$, with far gone degeneration, they are 18 per cent., 23 per cent., and 35 per cent. If I am right, then another conclusion may be drawn, that in the medium cases Müller's fibres remain free from degeneration for a longer time than the neuroglia. If they are limited to the disc they are very often congenital, and it is impossible by ophthalmoscopic examination to differentiate these from the pathological ones in the absence of other signs.

Change in the lumen of the vessel I have seen in one case, i.e., 4 per cent. in group No. 1 . And I am still in doubt whether it was an actual change or only a tonic muscular contraction of the media. It was 15 per cent. in group No. $1 a$ and 47 per cent. in group No. 1c. Very often the change of the lumen of the vessels is a sign of "athero-sclerosis" of the intima. I am under the impression that it is to be seen more frequently in the small cilioretinal arteries than in the branches of the arteria centralis retinae.

Tortuosity of the vessels may be a normal feature, as all authors agree. It is present in 30 per cent. of the cases in group No. 1 , 39 per cent. in group No. $1 a$, and 53 per cent. in group No. $1 c$.

The last and very important sign to discuss is the state of the veins when crossed by the arteries. In the normal eye the vein may only be depressed by the artery (11 per cent. in group No. 1), although de Schweinitz states that "ordinarily, as an artery crosses a vein, there is no sign of pressure." With increasing arterial hypertension the frequency of depression of the vein increases, 30 per cent. in group No. $1 a$, but decreases sharply in group No. $1 c$ : most of the veins are not depressed, but already crusher.

As a further stage the veins are crushed by the arteries. Isut 
there is not always an actual interference with the blood stream, as shown by interruption of the venous pulse or ampulliform dilatation of the distal end of the vein. It is 0 per cent. for the group No. 1, 27 per cent. for group No. $1 a$, and 41 per cent. for group No. $1 c$.

Crushing of the veins, accompanied by interference with the blood stream, is 0 per cent. for group No. 1,15 per cent. for group No. $1 a$, and 30 per cent. for group No. $1 c$. In nearly all cases the distal end of the vein is dilated, as is only to be expected. But in case No. $43 a$, in the left eye the venous pulse may be seen on the disc. It is interrupted by the crossing artery with an enlargement of the proximal end of the vein. Can this be explained by a further obstruction of the blood stream higher up in the trunk of the vena centralis, as was anatomically demonstrated by von Michel? This crushing may even be a local condition of the artery. Two crossings in the same eye (No. 3c) may be quite different in this respect. Foster Moore, of course, is right in explaining this crushing by the sclerosis of the artery. He explains in the same way the deflection of the vein. The centrifugal (from the disc towards the periphery or following the direction of the artery) deflection of the vein I have seen in 8 per cent. of group No. 1, as stated previously, in 9 per cent. in group No. $1 a$, and in 6 per cent. in group in No. 1c. But centripetal deflection I have seen in 3 per cent. in group No. $1 a$, and in 6 per cent. in group No. $1 c$.

In a few cases (Nos. 25a, 30a, 40a) the vein is deflected, but not crushed, by the artery. Possibly some significance must be attached to the fixation of the vessels at the point of crossing and to the sclerosis of the fibrous tissue.

\section{The Clinical Value of Arterial Hypertension.}

What is the normal blood pressure in man? For systolic pressure the table in Green's "Medical Diagnosis" is, in my opinion, correct. The French authors (Lyon) tried to construct a formula to deduce the normal diastolic pressure from the systolic, but as far as my knowledge goes, other authorities did not find this satisfactory. And the diastolic pressure is of the utmost importance, possibly even more so than the systolic one, as showing the permanent pressure under which the vascular system works. Personally, I am always alarmed if the diastolic pressure rises with a more or less constant systolic pressure. In one of my cases, to take an extreme one, the reading was $250 / 120,260 / 150,295 / 175$.

In my opinion the maximum normal diastolic pressure at the ages of 50-60 years is $90 \mathrm{~mm}$. Everything higher than that should be regarded as pathological. Green says (page 487) : "as a matter 
of practical application a decided and persistent hypertension with a high, or relatively high, diastolic level means chronic nephritis, until another cause is proved or rendered a reasonable assumption. (italics of Green). This statement holds good regardless of the absence of the classical urinary findings at the time that hypertension is becoming manifest. In other words chronic Bright's disease, with or without albumen and casts, but seldom without evidences of impaired renal permeability, is so commonly the cause as to place all other claimants among the 'possibilities' only."

Lewandowsky states: "Ein Blutdruck von 180-200 mm. $\mathrm{Hg}$ und höher beweist aber mit fast völliger Sicherheit' eine diffuse vasculäre Nephritis, am haufigsten in besonderen eine arteriosclerotische Schrumpfniere, auch dann wenn der Eiweiss in der Urine zurzeit nicht nachzuweisen ist" (p. 305). The problem is even more complicated than this: "Most authorities state that abnormal tension follows, rather than precedes, definite urinary findings, but the author believes this to be an exact reversal of the true sequence" (Green, page 262). Other authorities, like Batty Shaw or Langdon Brown in this country, agree that the arterial hypertension may for a long time precede actual anatomical changes in the vessels or in the kidney. "In hyperpiesis the kidneys may be normal" (Batty Shaw, p. 177). The ordinary examination of the urine-as regards specific gravity, sugar, and albumen, will not help much, as the reader can see for himself from my tables (groups No. $1 a$ and No. $1 c$ ). Of course the kidney efficiency test will clear up the diagnosis in most cases, but not in all.

Ramsay says: "The toxin being kept back in the blood still eludes the most diligent search. The organic chemist has not tests sufficiently sensitive to discover many of the subtle toxic products of Nature's laboratory. Any tests that have been proposed can be passed successfully by a kidney which, to clinical observation, is manifestly unable to cope with the demands being made upon it." The diagnosis of essential hyperpiesis and interstitial nephritis or, in other words, of secondary and primary kidney, is a very fine and difficult one, and here the ophthalmoscope helps us considerably.

I should not state the case in this form "either the kidney efficiency test or the results of the ophthalmoscopic examination." If a parallel can be drawn, I would compare the kidney efficiency test with the Wassermann reaction : if it be positive, it shows that the kidney is impaired - there can be no discussion, it is settled. But if the kidney efficiency test is doubtful or fairly good, but the ophthalmoscopic examination results in very grave suspicion of interstitial nephritis, I dare to say that I would be more inclined to rely upon the latter than upon the former. Look at the difference 
of the retinal changes in the cases Nos. $3 c, 4 c, 12 c, 13 c$ on the one hand, and No. $17 c$ on the other. Possibly the later history of this highly interesting case will clear up the diagnosis, if the migratory character of the patient does not deprive me of the opportunity.

Batty Shaw states that "both (hyperpiesis and eclampsia) may show changes in the retina which are generally accepted as indicative of grave renal disease, but which, as post-mortem examination shows, should merely be accepted as indicative of a grave toxaemia, not necessarily of grave renal disease. The retinal changes may occur without an association with chronic disease of the kidney."(14) What then is the cause of the ophthalmoscopic picture in such cases? Is it primary vascular degeneration or is it inflammation of the retina? The answer is of some importance. If the vascular changes be primary - then in the eye we see the process which is probably going on in the same degree all over the body. But if the retinitis be primary-then we have before us a picture of perverted metabolism in a highly developed and sensitive part of the body, which may be the first to indicate a retention of toxins usually eliminated by the kidneys. Even more, the possibility of some intimate relation between the retinal vessels and the excretory (endocrine?) activity of the kidneys may exist. Take the retinitis of pregnancy : why of all sense organs are the eyes chiefly affected? Truly, we cannot examine the state of the vessels of the ear, as we examine those of the retina. But from the classical symptoms of inflammation-tumor, rubor, calor, dolor, et functio laesa-the last one is easily demonstrated. Vision is always very considerably impaired in the retinitis of pregnancy. Why not the hearing or the taste, etc.?

Römer and von Michel, to quote from German authors, consider that in retinitis albuminurica "the whole picture of the disease is the result of a hyaline degeneration of the vessels."(13) Ramsay ${ }^{(12)}$ says that "vascular degeneration always precedes permanent structural changes, either in the kidney or in the retina, and consequently the most typical cases of albuminuric retinitis occur when an acute or subacute attack supervenes on previously existing chronic nephritis."

Other authorities think that in certain cases the changes in the retina come first and the vascular changes are only secondary to them. To quote from Poulard(11): "En somme les alterations vasculaires" (in retinitis albuminurica) "ne sont pas très marquées, elles n'ont ni la constance absolue, ni l'intensité, ni l'extension qu'on doit exiger des lésions considérés comme génératrice de toutes les autres" (Rochon Duvigneaud).

The last word is with the pathological anatomist. Only the microscope can settle the dispute. Ginsberg( ${ }^{(4)}$, when discussing 
the histology of retinitis albuminurica, says: "Die Blutgefässe sind meist, aber nicht immer verändert . . . . Doch können die Gefässe ziemlich normal sein: Treitel fand nur an einzelnen Venen geringe Verdickung der Adventitia mit spärlicher Einlagerung von Körnchenzellen ... J Jedenfalls dürfen die Netzhaut Veränderungen im allgemeinen aber wohl als entzündlich bezeichnet werden, nicht als einfach degenerativ."

Therefore, if the vascular changes are the cause of the retinitis, they would always be present. But if the vessels can be "fairly normal," evidently they are secondary in time and in importance, especially if we remember that in nephritis death does not occur quickly, but that the toxins have ample time to act upon the retina, before the eye comes to the pathological laboratory.

Therefore I think that we may have in retinitis a real pathological metabolism of the retinal cells; the tissue is highly organized, consists chiefly of nervous elements which cannot proliferate, but only degenerate, and this easily too, and the capillary net is very close and fine.

There is a parallel in arterial hypertension, as discussed previously: Is it the result of interstitial nephritis or is it a preexisting sign: The same unknown toxin-will it produce first essential hyperpiesis and later interstitial nephritis, or is there one toxin for hyperpiesis and another for interstitial nephritis?

I did not have a definite case of albuminuric retinitis in my series, possibly I was not lucky enough, or more probably such cases are more frequently seen in hospital practice. But in three cases : Nos. $17 c, 5 b$, and $4 b$, I saw a very fine oedema of the retina. It looked to me like a delicate veil covering the vessels. These can still be seen but dimly. Sometimes it appears as a wide band along some major branch of the central retinal artery, but in my experience it never leads to definite changes in the retinal structure. Sometimes it lasts a week or two, sometimes only a few days. As these cases have generally very markedly degenerated fundi the phenomenon is not easily seen, unless the eye is examined often or the examiner is lucky enough just to happen on it. In case No. $5 b$ I proved to be right. Cases Nos. $4 b$ and $17 c$ are, in my opinion, under grave suspicion, although in No. $17 c$ the kidney efficiency test is fairly good.

As a résumé, if a general practitioner has under his care a case of arterial hypertension, he can fairly well judge the question of interstitial nephritis, relying upon frequent urine tests and ophthalmoscopic examination. The kidney efficiency tests are, of course, desirable. But, unfortunately, the general practitioner is seldom in a position to carry them out on his patients, even with the benevolent help of a hospital. 


\section{Diabetes Mellitus}

The importance to the general practitioner of ophthalmoscopic examination in diabetes mellitus lies, in my opinion, in a different direction. If the urine be sugar-free, with or without insulin, is the patient really safe? In a medical paper, published two or three years ago, an article appeared stating that such was the case and that the blood-sugar estimation is practically unnecessary with insulin injections and frequent and careful testing of the urine. $\mathrm{l}$ cannot agree with this opinion. Case No. $4 b$ may be the tragic result of such an idea. Of course the estimation of sugar in the blood will settle the matter. But again, as with kidney efficiency tests, can it be easily performed in general practice? It is expensive; it must be performed often. And the hospitals, busy with their own work, cannot help the general practitioner much in this matter. But if the retina be only arterio-sclerotic in a mild degree, without haemorrhages, which occur so often, or without retinitis, and if the blood pressure be not high, he can feel more or less safe. If he sees retinal haemorrhages, he must be on guard, and the question will arise whether the dose of insulin is sufficient, especially if the blood pressure be rising. But if, in spite of proper anti-diabetic treatment the blood pressure continues to rise, especially the diastolic pressure, and the state of the retina grows worse, haemorrhages becoming larger, I would be very alarmed lest interstitial nephritis is not coming into play. I know how difficult it is to differentiate between the various forms of retinitis, and how closely they may resemble each other, but I think that even a general practitioner, knowing the clinical facts, as seen and easily determined in routine surgery work, may have a fair and just idea of what is happening to his patient, if he will combine all his investigations.

\section{Prognosis}

"Involutionary arterio-sclerosis results rather in the contraction of the spheres of mental and bodily activity than, as with hyperpiesis, in the imminence of the fell sergeant, Death-death by apoplexy, by cardiac defeat or by intercurrent acute pneumonia." (Allbutt's words, quoted by Langdon Brown.) "Pressures of $190-200+$ convey a threat and those of $220+$ mean that the sword overhead is suspended by a hair." (Green, page 486.) In the opinion of Marcus Gunn : "the prognosis in cases with advanced arterio-sclerotic changes is unfavourable." And he states that all his cases were fatal. This is, of course, the case; the prognosis is very serious indeed. Therefore the following case I consider as worthy of special attention. Mr. R., male, aged 63 years, was 
seen at the out-patient department of the London Jewish Hospital in 1923, with retinal haemorrhages in the right eye. The preliminary diagnosis was thrombosis of the central vein? Still he did not develop the picture of venous thrombosis. I followed him up for a few months : fine haemorrhages in the central part and in the periphery of the retina (both eyes), urine 1010, no sugar nor albumen. The systolic pressure, by accident, was not recorded, but I remember that it was well over 200, near to 250. Diastolic pressure, written down in his history, was 140. According to the rule the man must die, and in a relatively short time. But, neglecting the rules, he discharged himself from hospital. In the course of a few months the haemorrhages disappeared. The old man lives near me and is puzzling me as he is behaving in a quite normal and healthy manner. I examined him a few weeks ago. His age now is 66 years. His systolic blood pressure is 150 , diastolic 90 . He is carrying on his work as a tailor and he tells me that he feels better than he did three years ago. Fundi : translucency of the vessels gone; small vessels are tortuous. In the left eye a small artery, going to the macula, is nearly obliterated and the corresponding vein also. No signs of retinal haemorrhages now. In my opinion this case shows that Batty Shaw is right; there is a special toxin (or a combination of them?) peculiar to essential hyperpiesis, and it is pre-renal in its origin. The toxin disappeared, very luckily for the patient, and the body has gone back to normal. But some retinal changes are left, and these are permanent. Of course there is no question of primary kidney disease in this case.

O'Hare and Walker say: "The finding of retinal arteriosclerosis in patients with a normal or low blood pressure indicates the existence of a previous hypertension with a subsequent myocardial weakening or loss of vascular tone" (Foster Moore $\left.{ }^{(10)}\right)$. The case of $R$. and many others, as analyzed previously, contradict this. In many cases the explanation is more simple : the toxin is gone, either as the result of rational treatment or spontaneously, the hyperpiesis disappears, leaving permanent changes in the retinal vessels, but the heart and vascular system are quite good, from a clinical point of view, in a better state than when hyperpiesis was present. What can be said of the nature of this toxin?

I mentioned before that, in my opinion, the case of $\mathrm{R}$. does show that Batty Shaw is right in thinking that the toxin is of pre-renal origin. But, to quote Foster Moore again: "Batty Shaw believes that the difference between the arterio-sclerotic retinitis and renal retinitis is one of degree only; he believes that the haemorrhages, the white patches and slight changes in the disc, met with in arterio-sclerotic retinitis, differ only from those met with in renal 
retinitis, in their being called into existence by the slower operation of the blood-poisons, or by a decreased local tissue sensitiveness, or by the smaller amount of such poison arriving at the scene of action in the former case, as compared with the latter."

I think that the following case is unique and will clearly contradict this view of Batty Shaw: My panel patient, D., male, aged 42 years, always enjoyed good health and had always led an abstemious life. On March 28, 1926, he had a severe haematuria without any pain. Being afraid that the haematuria might be of malignant nature, I sent him with a letter to a hospital. I got a reply that most probably it was a case of hypernephroma. On May 26 he came to see me after a successful operation for removal of the left kidney. On July 6 I saw him again after he returned from the Convalescent Home. On July 18 I examined his eyes : translucency of the vessels gone, light reflex dotted, copper-wire colour of the arteries. Wide white stripes accompany the arteries and especially the veins over the disc and adjacent retina. R.E.Change in the calibre of the inferior retinal artery in one spot and very tortuous small vessels. Large veins are crushed by the arteries, the medium ones only depressed. The macula is pigmented, is of yellow-white colour and flattened. Vision $=4 / 4.5$. L.E.-The same as the right; vena retinalis inferior is deflected centripetally by the crossing artery. Commencing maculitis; vision $=4 / 6$, patient told me that he always had bad vision in this eye. General health good, weight 11 stone. Arterio-sclerosis of the first degree of the brachial arteries. Blood pressure 150/90, $145 / 95,140 / 85$ : urine normal, specific gravity, 1018-1020: Wassermann negative. His renal efficiency for the right kidney was normal (report from the hospital).

Of course it is my fault that I examined his eyes so late. But I did it only by chance, when coming to the end of my present investigations. Well, I think we can call his fundus an advanced clinical arterio-sclerosis of the retinal vessels (not athero-sclerosis), especially in view of the macular changes. But he never showed any oedema or exudation in the retina and his vision is good. His blood pressure is not high; arterio-sclerosis of the first degree one would expect at his age. Evidently the hypernephroma so upset the endocrine activity of the supra-renal gland (and kidney too?) that the retinal vessels have undergone serious and permanent changes in a short period of time without involvement, in the same degree, of the peripheral vascular system. Of course it is quite possible that he has an atheroma of the aorta or an arterio-sclerosis of the cerebral vessels, as it is impossible to investigate them. But as far as the peripheral vessels are concerned there is no reason to think that they are diseased, as they are soft enough to palpation and the blood pressure is not high. 
If we compare his case with experiments on animals, atheroma is much less probable than arterio-sclerosis. One would expect in this case, if Batty Shaw be right, a picture of renal retinitis, not of arterio-sclerotic retinitis. On the other hand, it seems to me, this case does illustrate that there is an intimate (hormonic?) connection between the activity of the kidneys and retinal vessels (or cerebral vessels too?).

The only explanation that I can give of this case is the following : the hyperplasia of the supra-renals may lead to an excessive secretion of adrenaline; this excess of adrenaline can be neutralized in the blood or not. If not, then it can favour the precipitation of ionic calcium. Experimentally arterio-sclerosis can be produced in animals by injections of adrenaline. "Comme action sur le metabolisme signalons encore l'infiltration calcair de la tunique moyenne des artères (arterio-sclerose experimentale) consecutive aux injections repetèes d'adrenaline" (Gley $\left.{ }^{(5)}\right)$. Unfortunately I never took his blood pressure before the operation nor was this done at the hospital.

\section{Conclusions}

(1) Sclerosis of the retinal vessels is recognized first of all by the loss of translucency of the vascular wall; other symptoms develop later. In a normal and healthy person this sclerosis may begin very late indeed, and may not be present even in advanced age, when the vessels of the other parts of the body are already stricken with arterio-sclerosis, if the blood pressure be normal.

(2) The same toxin which is the cause of essential hyperpiesis quickly develops arterio-sclerotic changes in the retinal vessels, even at a young age, if this arterial hypertension continues long enough. Its action may cease, and clinically the general vascular system may recover completely, but the arterio-sclerotic changes in the retinal vessels remain permanently.

(3) There is some reason to believe that the toxin of essential hyperpiesis is pre-renal in origin, but renal retinitis and arteriosclerotic retinitis are probably caused by different toxins. It is probable that there is some intimate connection between the state of the retina and activity of the kidney (endocrine?).

In conclusion it is my pleasant duty to express my thanks to $\mathrm{Mr}$. A. H. Levy for permission to use many of his cases and for his valuable assistance in the preparation of this paper. 
A.

A. R. INF.

A. R. S.

B. E.

C. W.

DitTo -

F. N.

L. R.

L. V.

L.

N.

R.

Tr. DIM.

TR. Pr.

TR.

TR. AB.

V.

V. D.

V. D. CF

V. CR. -

W. INT. BL.

W. S.

$\delta$

q
Arteries.

Arteria retinalis inferior.

Arteria retinalis superior.

Both eyes.

Copper wire.

Idem.

Fundus perfectly normal.

Light reflex.

Large vessels.

Left eye.

Normal.

Right eye.

Translucency diminished.

Translucency present.

Translucency of the vessels.

Translucency absent.

Veins.

Veins depressed.

Vein deviated centrifugally.

Veins crushed.

Without interruption of the blood streảm.

White stripes.

Male.

Female. 
Analytic Table.

\begin{tabular}{|c|c|c|c|c|c|c|c|c|c|c|c|}
\hline \multirow{2}{*}{\multicolumn{3}{|c|}{ 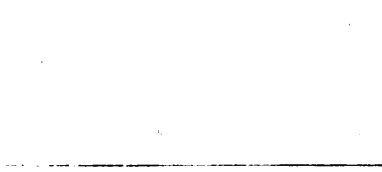 }} & \multirow{2}{*}{$\cdot$} & \multicolumn{2}{|c|}{$\begin{array}{l}\text { Normal } \\
(29 \text { cases })\end{array}$} & \multicolumn{2}{|c|}{$\begin{array}{c}\text { Moderate } \\
\text { hyper-- } \\
\text { piesis } \\
\text { (56 cases). }\end{array}$} & \multicolumn{2}{|c|}{$\begin{array}{l}\text { Diab. mell: } \\
\text { (8 cases). }\end{array}$} & \multicolumn{2}{|c|}{$\begin{array}{c}\text { Advanced } \\
\text { hyper- } \\
\text { piesis } \\
\text { (14 cáses). }\end{array}$} \\
\hline & & & & No. & $\%$ & No. & $\%$ & No. & $\%$ & No. & $\%$ \\
\hline \multirow{2}{*}{$\begin{array}{l}\text { Tran. present } \\
\text { Tran. partly pres. }\end{array}$} & $\cdots$ & $\cdots$ & ... & 26 & $100 \%$ & - & - & - & - & - & - \\
\hline & Tran. partly pres. ... & $\ldots$ & $\ldots$ & - & - & 2 & $3 \%$ & 1 & $12 \%$ & - & - \\
\hline Tran. absent & $\ldots$ & $\ldots$ & $\ldots$ & - & - & 54 & $97 \%$ & 7 & $88 \%$ & 17 & $100 \%$ \\
\hline L. ref. dotted & $\ldots$ & $\ldots$ & $\ldots$ & - & - . & 24 & $43 \%$ & 8 & $100 \%$ & 16 & $94 \%$ \\
\hline Copper w. art. & $\cdots$ & $\cdots$ & $\cdots$ & - & - & 23 & $41 \%$ & 8 & $100 \%$ & 15 & $88 \%$ \\
\hline Silver w. art. & $\cdots$ & $\cdots$ & $\ldots$ & - & - & - & - & - & - & 3 & $18 \%$ \\
\hline \multicolumn{3}{|c|}{ Lumen of the vess. changed } & $\ldots$ & 1 & $4 \%$ & 8 & $15 \%$ & - & - & 8 & $47 \%$ \\
\hline \multicolumn{3}{|c|}{ Tortuosity of the vessels... } & $\cdots$ & 8 & $30 \%$ & 22 & $39 \%$ & 3 & $37 \%$ & 9 & $53 \%$ \\
\hline \multicolumn{3}{|l|}{ Veins depressed } & ... & 3 & $11 \%$ & 17 & $30 \%$ & - & - & 1 & $6 \%$ \\
\hline \multicolumn{4}{|c|}{ Veins depressed and deflected .. } & 2 & $8 \%$ & 5 & $9 \%$ & $\begin{array}{c}1 \\
\text { (centri } \\
\text { petally }\end{array}$ & $12 \%$ & - & - \\
\hline \multicolumn{3}{|c|}{ Veins cr. w. int. bl. } & $\ldots$ & - & - & 15 & $27 \%$ & 2 & $25 \%$ & 7 & $41 \%$ \\
\hline \multicolumn{3}{|c|}{ Veins crushed with int. bl. } & $\ldots$ & - & - & 8 & $15 \%$ & 1 & $12 \%$ & 5 & $30 \%$ \\
\hline \multicolumn{4}{|c|}{ V. cr. and deviated centrifugally } & - & - & 5 & $9 \%$ & - & - & 1 & $6 \%$ \\
\hline \multicolumn{4}{|c|}{ V. cr. and deviated centripetally } & - & - & 2 & $3 \%$ & 1 & $12 \%$ & 1 & $6 \%$ \\
\hline \multicolumn{4}{|c|}{$\begin{array}{l}\text { W.s. accompany the vessels on } \\
\text { the crossing points only }\end{array}$} & 1 & $4 \%$ & 8 & $15 \%$ & 1 & $12 \%$ & 3 & $18 \%$ \\
\hline \multicolumn{4}{|c|}{$\begin{array}{l}\text { W.s. accompany the vessels over } \\
\text { the disc } \ldots \quad \ldots\end{array}$} & 2 & $8 \%$ & 15 & $27 \%$ & 1 & $12 \%$ & 4 & $23 \%$ \\
\hline \multicolumn{4}{|c|}{$\begin{array}{cccc}\text { W.s. accompany } & \text { the vessels on } \\
\text { the retina... } & \ldots & \ldots & \ldots\end{array}$} & - & - & 3 & $5 \%$ & - & - & 6 & $35 \%$ \\
\hline \multicolumn{3}{|c|}{ Gener. narrow. of the vessels } & $\ldots$ & - & - & 5 & $9 \%$ & - & - & 6. & $35 \%$ \\
\hline \multicolumn{3}{|c|}{ Discs not sharply outlined } & ... & - & - & 2 & $3 \%$ & - & - & 2 & $12 \%$ \\
\hline \multicolumn{2}{|c|}{ Oedema of the retina } & $\ldots$ & ... & - & - & - & - & 1 & $12 \%$ & 1 & $6 \%$ \\
\hline \multicolumn{3}{|c|}{ Old ret. haemorrh. (pigment) } & $\ldots$ & - & - & - & - & - & - & 2 & $12 \%$ \\
\hline \multicolumn{2}{|c|}{ Fresh ret. haemorrh. } & $\cdots$ & $\ldots$ & - & - & 1 & $1 \frac{1}{2} \%$ & 2 & $25 \%$ & 4 & $23 \%$ \\
\hline \multicolumn{2}{|c|}{ Exud. in the macula } & $\cdots$ & $\ldots$ & - & - & - & - & - & - & 2 & $12 \%$ \\
\hline
\end{tabular}




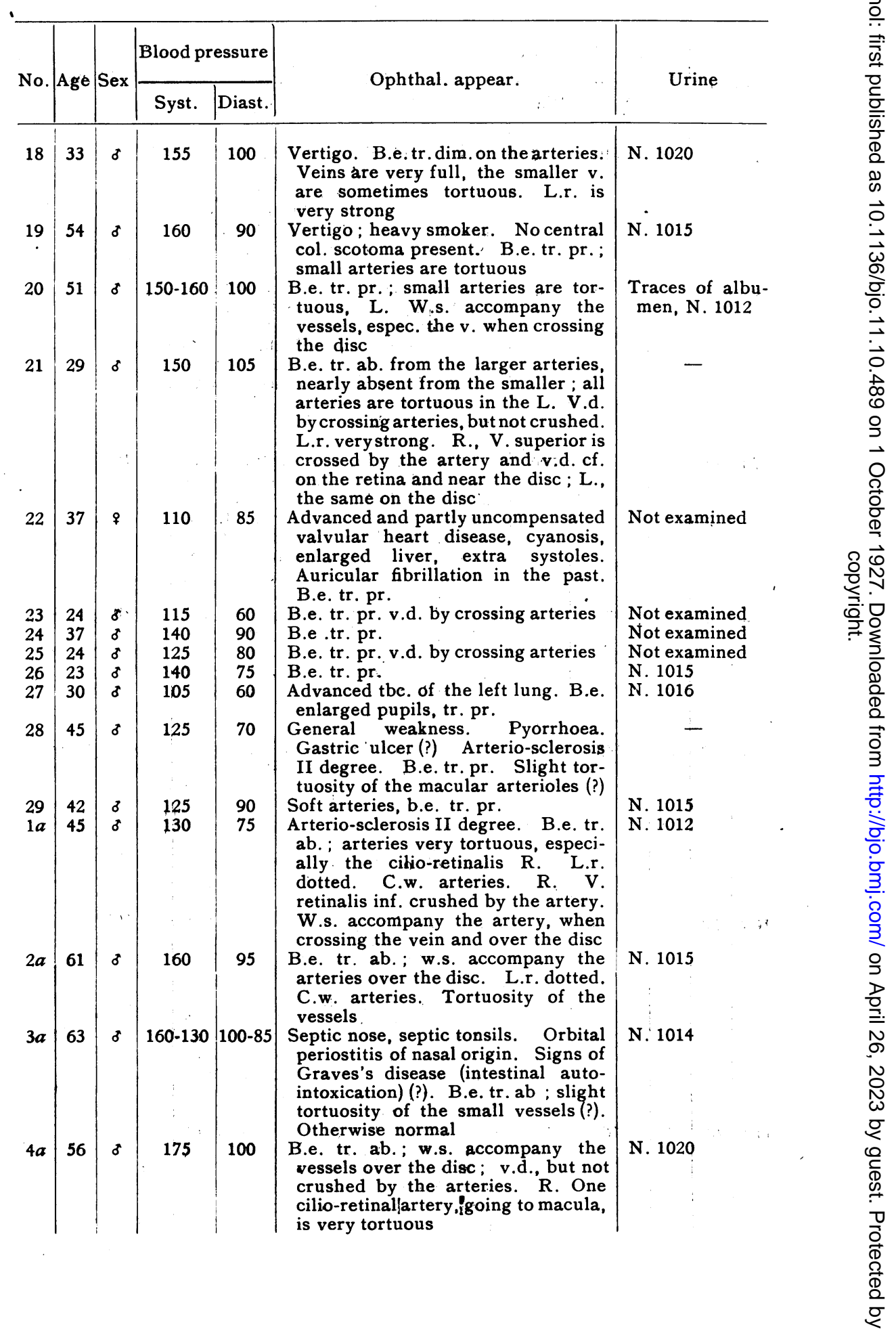




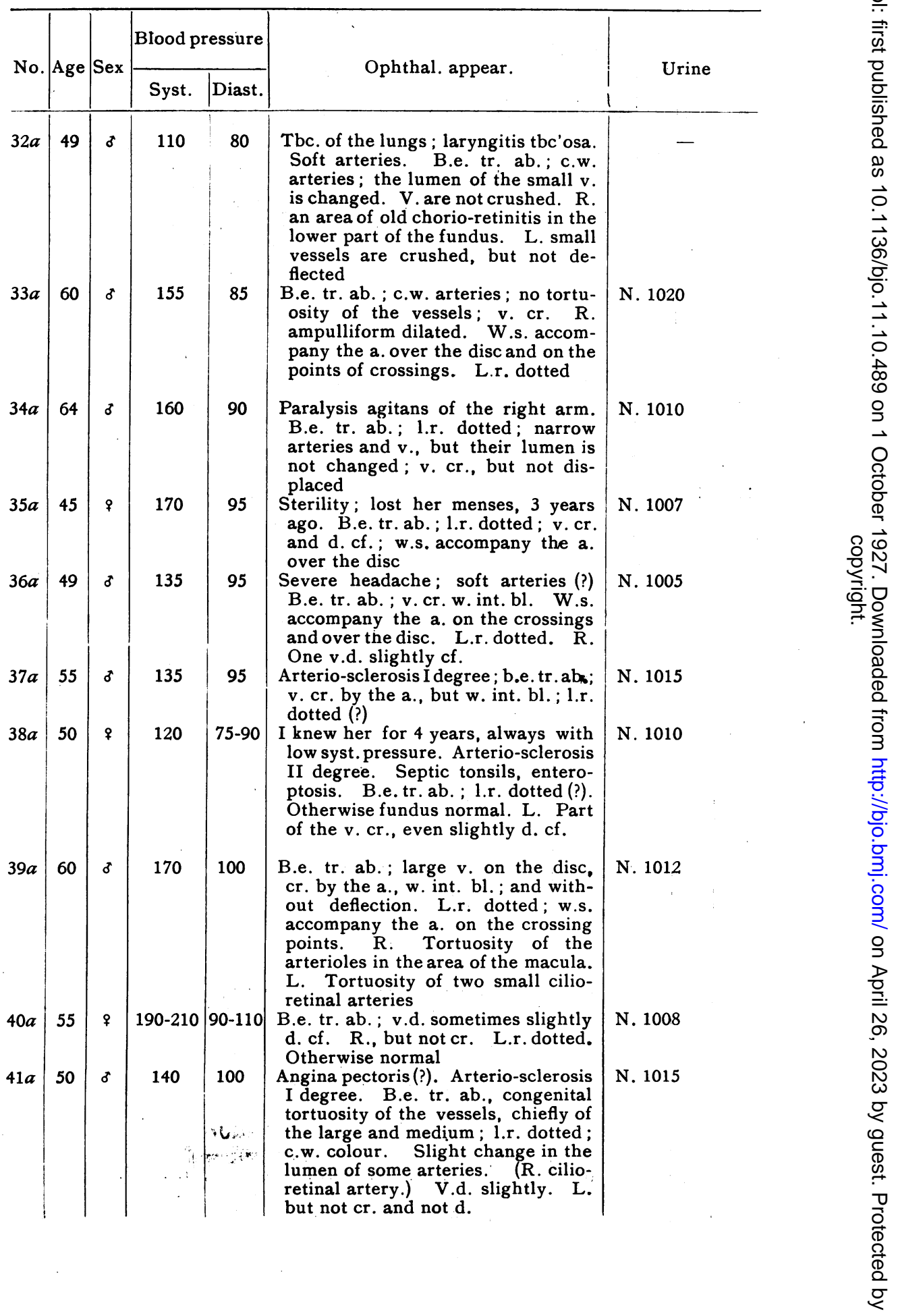




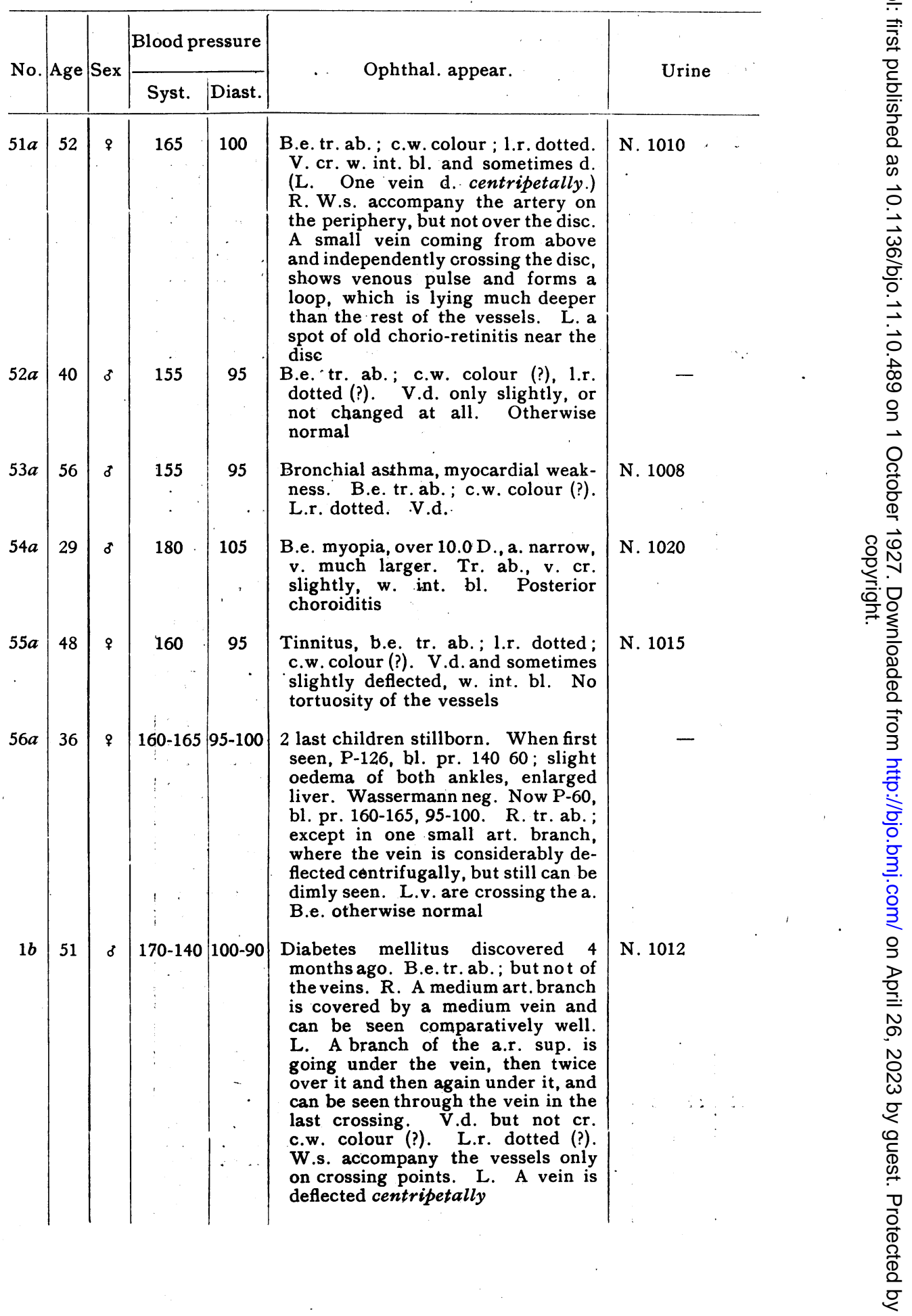




\begin{tabular}{|c|c|c|c|c|c|}
\hline \multirow{2}{*}{ No. } & \multirow{2}{*}{ Age } & \multirow{2}{*}{ Sex } & Blood pressure & \multirow{2}{*}{ Ophthal. appear. } & \multirow{2}{*}{ Urine } \\
\hline & & & Syst. Diast. & & \\
\hline
\end{tabular}

of the large and medium arteries. L.r. dotted (?). C.w. colour (?)

Diab. mell. for the last few years. Sugar free, if careful in diet. B.e. tr. ab. ; slight tortuosity of the small vessels. C.w. colour (?). L.r. dotted (?). One would pass her fundus as normal for her age

Suffered from diab. mell. for years. 3 years ago was put on insulin, when being in hospital, and remained under medical supervision. Her eyes were never examined all the time. I first examined her eyes in February, 1926. B.e. old and fresh retinal haemorrh., large ones; tr. ab. ; c.w. colour. L.r. dotted. White exudation in the macula, with haemorrhages in it. V.cr.w. int. bl. Very fine oedema of the retina, discs not quite clear, and not sharply outlined. I was under the impression that she was going to develop interstitial nephritis. 2 months later her bl. pr. was $\frac{164}{70}$ B.e. practically the same, except that the fine oedema of the retina was gone and the discs were of normal outline. Her blood urea was 0.25 mgrm. \%; her bl. sugar 0.143 . With 30 units insulin a day bl. sugar 0.092. She developed signs of hypoglycaemia; insulin was stopped and her bl. sugar rose to 0.225 . With 10 units daily 0.216 . On the $30 / 6 / 26$ she turned comatose with sugar and traces of acetone in her urine. 80 units of insulin same day; urine free from sugar and acetone. Died in a comatose state 48 hours later. 24 hours before death sudden clonic fits of all limbs and twitching of the face. Hemiplegia of the right side. No. P.M. performed. Probable cause of death cerebral haemorrhage or uraemia men. N. 1020

Traces of albumen. N. 1012 


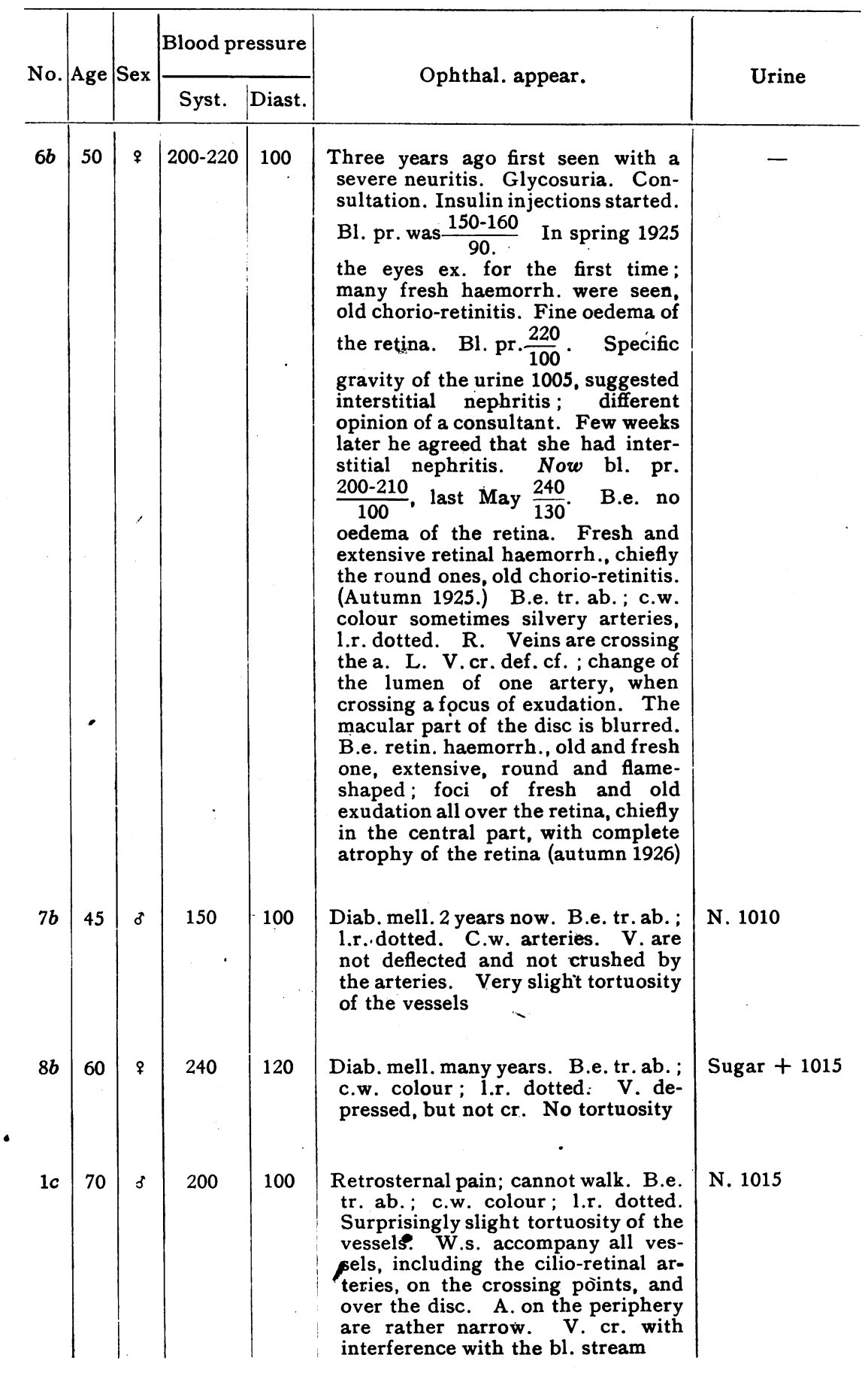


The British Journal of Ophthalmology

\begin{tabular}{|c|c|c|c|c|c|c|}
\hline \multirow{2}{*}{ No. } & \multirow{2}{*}{ Age } & \multirow{2}{*}{ Sex } & \multicolumn{2}{|c|}{ Blood pressure } & \multirow{2}{*}{ Ophthal. appear. } & \multirow{2}{*}{ Urine } \\
\hline & & & Syst. & Diast. & & \\
\hline $11 c$ & 54 & ㅇ & 200 & 110 & $\begin{array}{l}\text { Sterility; gout ; b.e. myopia } 13.0 \mathrm{D} . ; \\
\text { post. choroiditis. Tr. ab. ; c.w. } \\
\text { colour; } 1 \text {.r. dotted, narrow arteries, } \\
\text { large veins. V.d. by crossings. } \\
\text { Opacities of the lens }\end{array}$ & N. 1005 \\
\hline $12 c$ & 56 & 운 & $\begin{array}{l}210 \\
200 \\
210 \\
190 \\
190 \\
180 \\
240\end{array}$ & $\begin{array}{r}110 \\
90 \\
100 \\
100 \\
90 \\
90 \\
110\end{array}$ & $\begin{array}{l}\text { Known to me for } 5 \text { years. Started } \\
\text { with attack of minor uraemia (head- } \\
\text { ache, epigastric pain, sickness, "air- } \\
\text { hunger," fainting) B.e. tr. ab.; } \\
\text { c.w. colour; 1.r. dotted. V. cr.; } \\
\text { but without interference with the } \\
\text { blood-circulation. L. A striking } \\
\text { change in the lumen of one vein } \\
\text { All v. are more crushed than in the } \\
\text { right eye. R. The small a. are } \\
\text { tortuous }\end{array}$ & $\begin{array}{l}\text { Traces of albu- } \\
\text { men. N. } 1000- \\
1005\end{array}$ \\
\hline $13 c$ & 50 & $q$ & $\begin{array}{l}220 \\
260 \\
290 \\
300 \\
310 \\
290 \\
260\end{array}$ & $\begin{array}{l}110 \\
125 \\
140 \\
150 \\
160 \\
170 \\
150\end{array}$ & $\begin{array}{l}\text { Known to me for } 4 \text { years. First stroke } \\
3 \text { years ago with the involvement of } \\
\text { the n. facialis dexter: only. The } \\
\text { second stroke } 2 \text { yearsago, with hemi- } \\
\text { plegia sinistra. The majority of the } \\
\text { movements restored by now. Last } \\
\text { year's kidney efficiency test-good } \\
\text { result. B.e. tr. ab.; c.w. colour; } \\
\text { l.r. dotted. Slight tortuosity of the } \\
\text { a. V. cr. moderately, w. int. bl. } \\
\text { L. W.s. accompany one artery in } \\
\text { the periphery. A small spot of } \\
\text { chorio-retinitis near the macula }\end{array}$ & - \\
\hline $14 c$ & 50 & $\delta$ & 210 & 100 & $\begin{array}{l}\text { Acute nephritis with oedema of the } \\
\text { legs } 3 \text { years ago. B.e. tr.ab.; colour } \\
\text { of the a. is silvery; l.r. dotted. } \\
\text { Change in the lumen of the a. W.s. } \\
\text { accompany one small branch of the } \\
\text { a. ret. sup.; a large white track } \\
\text { accompanies the a. ret. infer. }\end{array}$ & - \\
\hline $15 c$ & 65 & q & $190-200$ & 110 & $\begin{array}{l}\text { For the last } 2 \text { years suffered from } \\
\text { attack of tachycardia. Hysteria. } \\
\text { B.e. lens opacities; tr. ab.; c.w. } \\
\text { colour; 1.r. dotted. A. are tortuous. } \\
\text { v. cr. w. int. bl. }\end{array}$ & N. 1005 \\
\hline $16 c$ & 67 & q & $210-220$ & $\begin{array}{l}110- \\
115\end{array}$ & $\begin{array}{l}\text { B.e. tr. ab. ; c.w. colour; } 1 . r \text {. dotted. } \\
\text { Change in the lumen of the a. V.cr. } \\
\text { w. int. bl. W.s. accompany the a. } \\
\text { on the crossing points. R. A small } \\
\text { haemorrhage over the disc from a } \\
\text { small artery?. L. Old arterio- } \\
\text { sclerotic maculitis - pigmentation, } \\
\text { white exudation, flattening of the } \\
\text { macula }\end{array}$ & $\begin{array}{c}\text { Traces of albu- } \\
\text { men. N. } 1010\end{array}$ \\
\hline
\end{tabular}


Arterial Hypertension and Retinal Changes

\begin{tabular}{|c|c|c|c|c|c|c|}
\hline \multirow{2}{*}{ No. } & \multirow{2}{*}{ Age } & \multirow{2}{*}{ Sex } & \multicolumn{2}{|c|}{ Blood pressure } & \multirow{2}{*}{ Ophthal. appear. } & \multirow{2}{*}{ Urine } \\
\hline & & & Syst. & Diast. & & \\
\hline $17 c$ & 48 & q & 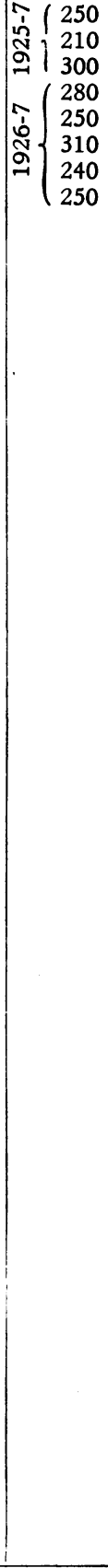 & $\begin{array}{l}110 \\
130 \\
150 \\
150 \\
140 \\
160 \\
140 \\
150\end{array}$ & 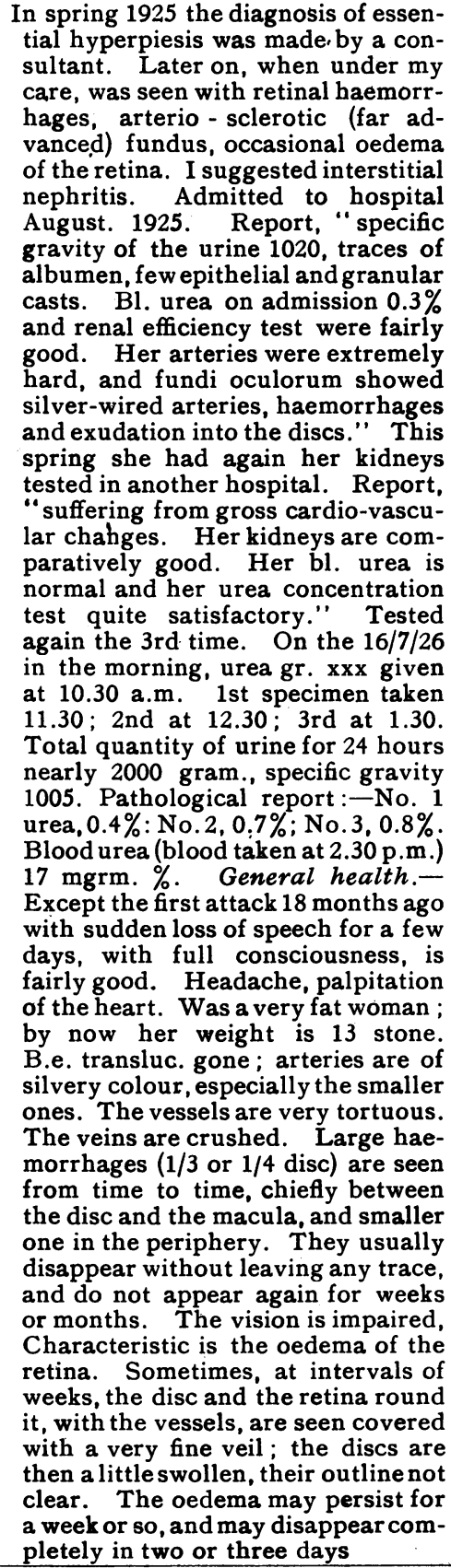 & 一 \\
\hline
\end{tabular}




\section{REFERENCES}

1. de Schweinitz.-Diseases of the eye. 1921.

2. Fuchs.-Textbook of ophthalmology. 1924.

3. Fox.-A practical treatise on ophthalmology. 1920.

4. Ginsberg.-Grundriss der Pathologischen Histologie des Auges. Berlin, 1903.

5. Gley.-Physiologie. 1924.

6. Green.-Medical diagnosis. 5th edition.

7. Gunn, Marcus.-Trans. Ophthal. Soc. U.K. 1898.

8. Lewandowsky.-Praktische Neurologie fur Aerzte. 1919.

9. Brown, Langdon.-Physiological principles in treatment. 1924.

10. Moore, Foster.-Medical Ophthalmology, Chapter II, 1922.

11. Poulard.-Traité d'ophtalmologie. 1924.

12. Ramsay, A. M.-Ocular disturbances in functional inefficiency of the kidney. Glasgow Med. Jl., 1925.

13. Römer.-Handb. der Augenkrank. Russian edition, 1913.

14. Shaw, Batty.-Hyperpiesia and Hyperpiesis. 1922.

15. Salzmann, M.-Die Anat. und Histol. d. Norm. Menschl. Auge. 1913.

16. Lyon, G. - Traité elem. de clinique thérapeut. 1924.

17. Lister, A. E. J.-Ophthalmology. Med. Annual, 1926.

\section{ANNOTATION}

\section{Miners' Nystagmus}

There have recently been many communications published on the subject of miners' nystagmus. Dr. Freeland Fergus, whose practical experience of the disease entitles his opinion to considerable respect, states his views at some length in the British Medical Journal, June 18, 1927 (an abstract of the paper will be found on page 525 of this number). He rejects the findings of the Nystagmus Committee respecting the defective light theory or at least regards them as not proven. He points out that the introduction of electric light has not always been followed by any improvement in the nystagmus statistics, and even in some cases nystagmus seems to have increased. He says : "No doubt we may be told that it is because the best type of electric lamp has not yet been procured and the coal owners may be called upon to face further great expense on that head. I think that before any such demand is made of them, there should be a much more thorough investigation into the cause of the disease, which investigation would include a well organized collective investigation throughout the entire coal fields of the United Kingdom. Such a research ought unquestionably to be in the hands of persons competent to deal with vital statistics and with public health." We trust he does not desire another Commission. Professor Haldane and Mr. Lister Llewellyn reply to this criticism of the work for which they were largely responsible in a very temperate letter (Brit. Med. Jl., July 2, 1927). They point out that the evidence that the essential cause of the disease 